Alma Mater Studiorum - Università di Bologna DEPARTMENT OF ECONOMICS

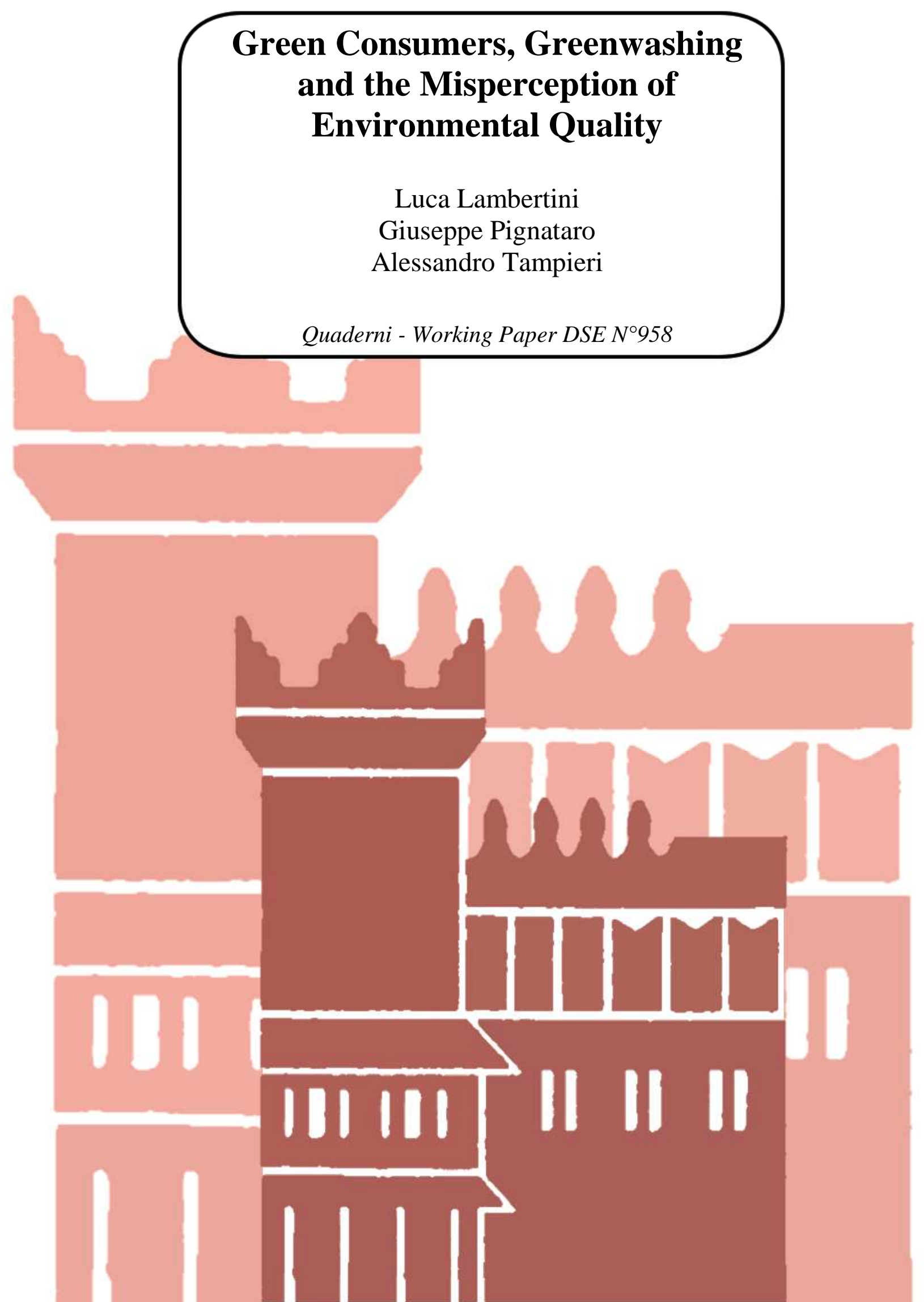




\title{
Green Consumers, Greenwashing and the Misperception of Environmental Quality
}

\author{
Luca Lambertini; Giuseppe Pignataro' \\ Alessandro Tampieri ${ }^{\ddagger}$
}

August 4, 2014

\begin{abstract}
In this paper we analyse a setup where consumers are heterogeneous in the perception of environmental quality. The equilibrium is verified in a setting with horizontal and vertical (green) differentiation. Profits are increasing in the misperception of quality, while, the investment in green quality decreases the more the goods are substitutes. We further consider the introduction of either an emission tax or an environmental standard. The former rises the investment in environmental quality due to the higher cost of production, whereas in equilibrium quality always improves after the introduction of the latter. We show that an optimal environmental standard is an effective regulatory instrument against greenwashing and that the efficacy of the interventions is conditioned to the damage distribution and the aggregate level of emission.
\end{abstract}

JEL codes: L13, L51, Q50.

Keywords: Green quality; Misperception; Pigouvian taxation; Environmental Standard.

${ }^{*}$ Department of Economics, University of Bologna, Strada Maggiore 45, 40125 Bologna, Italy; luca.lambertini@unibo.it.

${ }^{\dagger}$ Department of Economics, University of Bologna, Strada Maggiore 45, 40125 Bologna, Italy; giuseppe.pignataro@unibo.it.

${ }^{\ddagger}$ Faculty of Law, Economics and Finance, University of Luxembourg, Avenue de la Faïencerie 162a, L - 1511 Luxembourg; tamp79@gmail.com. 


\section{Introduction}

Access to knowledge and innovations in technology have led to increasing awareness of environmental issues. Several studies have shown that world-wide, consumer's appetite for green products has increased significantly in the past years (Chase and Smith, 1992; Kim and Choi, 2005; Chen, 2008, inter alia). Communities demand cleaner environments and the rise of consciousness has resulted in significant environmental improvement (Reitman, 1992). More companies around the world have reacted by developing eco-friendly products (Kohl, 1991; Chang, 2011). The eco-label is, for instance, one of the practises which allows consumers to identify the quality and the environmental consequences of a production process generally unobservable.

The role of information diffusion and the quality perception have been partially underscored in studies dealing with environmental policies. ${ }^{1}$ Environmental regulation in the literature is usually viewed as a form of agency issue where the polluting firms have better information about the true level of their abatement activities than the regulator. If certain aspects of environmental quality are costly to measure, regulators may resort to proxies to infer information about environmental quality. This may allow firms to circumvent the regulatory constraints by maximizing along those margins that are costly to measure (Bansal and Gangopadhyay, 2003).

In this paper, instead, an alternative perspective is proposed. We investigate the effect of environmental regulation when green consumers misperceive the quality of the products. In reality, there is a perception in the marketplace that a green package equals greater value. With little knowledge to make an informed decision, individuals seem to rely on firms' packaging to understand the positive (or negative) impact of production. This should not come as too much of a surprise, as consumers have traditionally lacked a detailed understanding of green innovation. Part of the consumers would undertake larger green consumption if they better understood the impact that each production has on the society. Others would confuse the level of transparency when there are no specific criteria qualifying a product as green. ${ }^{2}$ The benefits by appearing to be a green company come in the form of a higher stock price, more customers or favoured partnerships with green organisations (Doni and Ricchiuti, 2013). Thus paradoxically, higher prices are more easily understood by consumers with respect to other features, especially when comparing products and green investments across categories. They implicitly suggest significant eco-investments of the firms and justify payback period facilitating consumer decisions on those products.

This marketing strategies in order to appear environmentally friendly, i.e., greenwashing, usually occurs when a company spends more time and money claiming green production through advertising and marketing than actually implementing business practices that minimize environmental impact. ${ }^{3}$ Firms may operate in a way that is damaging

\footnotetext{
${ }^{1}$ An interesting exception relies on the signaling framework proposed by Sengupta (2012a).

${ }^{2}$ For instance most of the products that make the claim are biodegradable, phosphate and chlorine free may still derive their ingredients from petrochemicals like crude oil or natural gas (which are not renewable). https://www.gmaonline.org/downloads/research-and-reports/greenshopper09.pdf

${ }^{3}$ The tools used in greenwashing can include press releases about green projects or task forces put
} 
to the environment or in an opposite manner to the goal of the announced initiatives. ${ }^{4}$ Since consumers' evaluation is based on advertising to make decisions, greenwashing distorts their confidence (Hamann and Kapelus, 2004) and therefore it is positively associated to confusion and perceived risk (Chen and Chang, 2013).

This paper presents a model of regulation in the presence of asymmetric information of environmental quality. Our framework is characterized by the heterogeneity of consumers due to environmental awareness. We model the difference in consumers' environmental concern as a difference in their level of information. Indeed, like consumer consciousness (and perhaps related to it), the stringency of public regulation may have different effects according to the misperception of the market. Throughout the paper, we focus on the extent and manner in which the quality perception of conscious consumers induces different environmental performances and analyse their impacts of aggregate qualities. We treat regulation as exogenous and abstract from information problems between the regulator and firms. The aim is to understand how changes in regulation may influence the incentive of firms to invest in green technology or realising greenwashing behaviour.

In the baseline model, we evaluate the unregulated equilibrium and examine the variation in terms of under- (over-) estimation of the true quality. The equilibrium is symmetric. Profits in equilibrium are increasing in the perception, while, the investment in green quality decreases the more the goods are substitutes. Indeed, a higher degree of substitutability implies higher competition. Thus firms react by softening their investment in environmental quality. The paper considers next two government interventions.

First we investigate the effect of a tax on polluting emissions. This policy increases the investment in environmental quality due to changes on firms' incentives. The idea is that a company invests in green quality not only to acquire green consumers, like in the baseline model, but also to reduce tax burdening. We investigate next the introduction of an endogenous tax. The level of optimal taxation increases with the marginal damage on emissions if the average perception of environmental quality is high. A higher perception of environmental quality implies larger demand. If the marginal damage of emission is high, at the optimum, the increase in demands needs to be compensated by higher taxation. Moreover, the optimal tax decreases with the average perception of environmental quality if the marginal damage of emission is high. When production is very polluting, the optimal tax burden is heavy, but if the perception of environmental quality is high, the demand is so large that a lower level of taxation is sufficient to reach the optimum.

The second intervention regards the environmental standard. Despite of the downward sloping firms' reaction functions in quality which imply negative strategic effects, the impact of an environmental standard is that of increasing the perceived environmental quality even for consumers who underestimate quality. This effect rises their

into place, energy reduction or pollution reduction efforts, and rebranding of consumer products and advertising materials.

${ }^{4}$ Lyon and Maxwell (2011) analyse greenwashing as a game between a firm and an activist. In their analysis, greenwashing implies that the firm selectively discloses the positive information about their environmental or social performance without full revealing negative information. 
willingness to pay for the goods, while increasing firms' profits. The results explain the producers' willingness to accept the introduction of a standard. Instead, an endogenous environmental standard bites if the overestimation of environmental quality of some consumers is very high. The overestimation is positively related to greenwashing since the investment in green advertising induces consumers to overstate the environmental quality of the product. Firms invest more in environmental quality due to an optimal environmental standard representing an effective regulatory instrument in case of greenwashing.

The economic literature has recently analysed the presence of green consumers. A first group of papers focused on the impact of a higher consumers' consciousness on the market equilibrium and the associated social welfare (Eriksson, 2004 and Con$\mathrm{rad}, 2005)$. A second group dealt with the presence of green consumers interacts with the optimal environmental policy (Arora and Gangopadhyay, 1995, Cremer and Thisse, 1999, Moraga-Gonzales and Padron-Fumero, 2002, Lombardini-Riipen, 2005). Finally, the presence of green consumers has been examined in relation with socially responsible firms (Rodriguez-Ibeas, 2007, Garcia-Gallego and Georgantzis, 2009, Doni and Ricchiuti, 2013), or in determining the validity of the Porter hypothesis (Andrè et al., 2009, Lambertini and Tampieri, 2012). The common framework of these contributions is the pure vertically differentiated duopoly. Unlike these approaches, our framework considers both horizontal and vertical differentiation and goods differ in the degree of substitutability and in (environmental) quality.

The remainder of the paper is organised as follows. Section 2 introduces the model. Section 3 shows the baseline results. Section 4 consider the regulated equilibrium through two interventions, namely, the introduction of either a tax on emission or a standard of environmental quality with a simple simulation comparing their effect on quality. These regulatory interventions are developed and compared in Section 4.1, 4.2 and 4.3, respectively. Concluding remarks are proposed in Section 5.

\section{The model}

Consider an economy with two firms, each producing one differentiated good. Firms compete by choosing the environmental quality level of their products and their prices. ${ }^{5}$ There is a number of consumers with mass normalised to 1 . Their representative utility function, $U\left(x_{1}, x_{2}\right)$, is: ${ }^{6}$

$$
U\left(x_{1}, x_{2}\right)=\left(\alpha+e_{1}\right) x_{1}+\left(\alpha+e_{2}\right) x_{2}-\frac{x_{1}^{2}+2 \beta x_{1} x_{2}+x_{2}^{2}}{2}+c_{0},
$$

where $x_{i}$ denotes the representative consumer's quantity of good $i, i \in\{1,2\} ; e_{i}$ represents the environmental quality of good $i ; c_{0}$ is the quantity of the numeraire good;

\footnotetext{
${ }^{5}$ Note that the demand function takes into account both horizontal and vertical differentiation, while, the information technology is the same between firms.

${ }^{6}$ See Häckner (2000).
} 
while, $\beta \in[0,1]$ denotes the degree of substitutability between the two goods, with $\beta=0$ identifying independent goods and $\beta=1$ in case of perfect substitutes. ${ }^{7}$ Under symmetric information, consumers are perfectly aware of the intrinsic environmental quality of goods 1 and 2. ${ }^{8}$ For each $i \in\{1,2\}$, utility maximisation with respect to $x_{1}$ and $x_{2}$ gives a certain demand function:

$$
x_{i}\left(p_{i}, p_{j}, e_{i}, e_{j}\right)=\frac{\alpha(1-\beta)+\left(e_{i}-\beta e_{j}\right)-p_{i}+\beta p_{j}}{1-\beta^{2}}, j \in\{1,2\}, j \neq i .
$$

The rise in consumers' ecological consciousness is constrained by the fact that often they do not have sufficient information about the environmental quality of firm's production. We model this uncertainty in environmental consciousness as a case of imperfect information in detecting the environmental quality. Environmental perceptions are independent draws. The consumer's signal about the quality of good $i$ is $\rho_{i}, i \in\{1,2\}$. Only a proportion $\lambda \in(0,1)$ of the population recognises the true quality. In this case they $(i)$ are aware that the environmental damage are harmful for them and (ii) perceive the correct quality of the good $i$, i.e., $\rho_{i}=e_{i}$. A partial environmentally aware agents may instead capture interesting aspects. For instance companies use their ads and marketing campaigns to mislead consumers, by overstating claims of their environmental performance. ${ }^{9}$ For $i \in\{1,2\}$, a proportion of $1-\lambda$ consumers do not recognise the true environmental quality. It is equiprobable that they expect low quality $\rho_{i}=e_{0}$ or high quality $\rho_{i}=e_{m}>e_{0}$. The symmetry in the probabilities of the events is for the sake of simplicity. It has the advantage of keeping the analysis tractable to examine the impact of wrong perception of goods. The interpretation of a consumer with uncertain perception is therefore:

- $\rho_{i}=e_{0}<e_{i}$ : the consumer might underestimate the environmental quality of good $i$

- $\rho_{i}=e_{m}>e_{i}$ : the consumer might overestimate the environmental quality of good $i$.

Let us define $e_{0}$ and $e_{m}$ as the underestimation and the overestimation of environmental quality, respectively. In particular, $e_{m}$ can be interpreted as a measure of green washing. It implicitly infers the firm's practise of making unwarranted or overblown claims of sustainability or environmental friendliness in an attempt to gain market share. The higher the signal $e_{m}$, the larger the consumers' overperception of the environmental quality of the good. The (expected) proportion of consumers that receive the correct information about the environmental quality of both goods is $\lambda^{2}$. Then, a proportion of $(1-\lambda)^{2}$ of consumers are expected to receive wrong information about both goods,

\footnotetext{
${ }^{7}$ A similar procedure is proposed by Garella and Petrakis (2008). They analyse the effect of introducing a minimum quality standard when consumers are not perfectly informed of goods' quality.

${ }^{8}$ Note that quality enters in the intercept of the utility function. Symeonidis (2003) considers the alternative approach in which qualities alter the slope of the demand functions.

${ }^{9}$ See Delmas and Lessen (2014) for a field experiment on this issue.
} 
whereas $2 \lambda(1-\lambda)$ are expected to perceive wrong information about at most one of the goods. Furthermore, there are four equiprobable realisations of perceptions pairs $\left(e_{0}, e_{0}\right),\left(e_{m}, e_{m}\right),\left(e_{0}, e_{m}\right)$ and $\left(e_{m}, e_{0}\right)$, for individuals misperceiving the quality of both goods. There are two equiprobable realisations for consumers with perception of good 1 , namely $\left(e_{0}, e_{2}\right)$, and $\left(e_{m}, e_{2}\right)$. Similar results for good 2. According to the perceived differences on quality, the demand for good 1 by $N=1$ ex-ante identical consumers is given by:

$$
\begin{gathered}
q_{1}=\lambda^{2} x_{1}\left(e_{1}, e_{2}\right)+ \\
\frac{\lambda(1-\lambda)}{2}\left[x_{1}\left(e_{1}, e_{m}\right)+x_{1}\left(e_{0}, e_{2}\right)+x_{1}\left(e_{1}, e_{0}\right)+x_{1}\left(e_{m}, e_{2}\right)\right]+ \\
\frac{(1-\lambda)^{2}}{4}\left[x_{1}\left(e_{0}, e_{0}\right)+x_{1}\left(e_{m}, e_{0}\right)+x_{1}\left(e_{0}, e_{m}\right)+x_{1}\left(e_{m}, e_{m}\right)\right] .
\end{gathered}
$$

We thus represent nine types of consumers: one group of fully aware consumers, four groups of partially aware ones and the last four groups of wrongly aware consumers. Substituting in (3), the demand $q_{i}$ is:

$$
q_{i}\left(p_{i}, p_{j}, e_{i}, e_{j}\right)=\frac{(1-\beta)\left(\alpha+\frac{1}{2}\left(e_{m}+e_{0}\right)\right)+\lambda\left(e_{i}-\beta e_{j}\right)-p_{i}+\beta p_{j}}{1-\beta^{2}} .
$$

The role of information diffusion and absorption is crucial in this analysis. The demand function of firm $i$ always increases with the average value of quality misperception, i.e., $\bar{e}=\frac{1}{2}\left(e_{m}+e_{0}\right)$. Intuitively, consumers' appetite for green products leads firms to put forward the better ecological quality of a given product. As discussed above, the ecolabels, for instance, are some of the instruments used by firms to win market shares thanks to a differentiation strategy surfing the wave of consumers' ecological awareness. Since the environmental consequences of the production and the consumption of a product are generally unobservable, the eco-label appears as one of the way for consumers to collect such information. The higher the average misperception in quality induced by firms, the larger the demand for that good.

Consider next the supply side. Each firm produces one of the two goods. We normalise marginal costs of production to zero, while fixed costs are increasing in quality:

$$
C_{1}=e_{1}^{2}, C_{2}=e_{2}^{2}
$$

Thus the profit of firm $i$ is:

$$
\pi_{i}=p_{i} q_{i}\left(p_{i}, p_{j}\right)-C_{i}
$$

In the spirit of Arora and Gangopadhyay (1995), emission in the industry is regulated such that each firm is required to reduce emission at an endogenous quality level $e_{i}$, $i \in\{1,2\}$. Production goes along with pollutant at the level $\bar{E}$. Here quality in emission is a proxy for any kind of reduction on environmental damage. The net level of emission is therefore $E=\bar{E}-\left(e_{1}+e_{2}\right)$, where $E>0$. This assumption rules out the unrealistic case in which investing in green quality more than offset pollution. Indeed although new technologies and cleaner fuel can help cut down emissions of pollutants into the 
atmosphere, they are not replacing the non-green conventional production eliminating definitively the environmental damage. The damage value is assumed as a quadratic function of emissions, $D=d E^{2}$, where $d$ relies on the marginal damage of emissions. ${ }^{10}$ Consumer surplus, $C S$, is computed as the weighted average of the aggregate utility of all consumers' types. For instance, the utility of the consumers who are fully aware of goods 1 and 2 quality is given by:

$$
U\left(x_{1}, x_{2}\right)=\left(\alpha+e_{1}^{*}\right) x_{1}+\left(\alpha+e_{2}^{*}\right) x_{2}-\frac{\left(x_{1}^{2}+x_{2}^{2}+2 \beta x_{1} x_{2}\right)}{2}-p_{1}^{*} x_{1}-p_{2}^{*} x_{2} .
$$

Similar for the other groups. ${ }^{11}$ Thus social welfare in the society is given by:

$$
S W=\sum_{i}^{1,2} \pi_{i}+C S-D .
$$

The timing of the game is as follows. In the first stage, firms choose the level of environmental quality. In the second stage, firms compete in prices. The equilibrium concept is the subgame perfect equilibrium by backward induction.

\section{Baseline results}

Begin by the market stage. Each firm $i$ maximises profits with respect to $p_{i}$. The equilibrium price is

$$
p_{i}^{*}\left(e_{i}, e_{j}\right)=\frac{\left(2-\beta-\beta^{2}\right)[\alpha+\bar{e}(1-\lambda)]+\lambda\left[e_{i}\left(2-\beta^{2}\right)-\beta e_{j}\right]}{4-\beta^{2}},
$$

where $p_{1}^{*}=p_{2}^{*}$ if and only if $e_{1}=e_{2}$. The equilibrium price of firm $i$ is decreasing in the quality level chosen by its rival, $e_{j}$. Intuitively, a rise in consumers' consciousness increases their willingness to pay for environmental quality and reflects a higher consumer's marginal utility when they buy a green product. When a rival's quality increases, the premium commanded by one's own quality level at equilibrium is monotonically reduced. Indeed, the whole demand function to firm $i$ is shifted down. This negative effect is higher the larger the degree of the substitutability between the two goods, $\beta$. The positive effect of perceived environmental quality $\bar{e}$ on higher prices supports the idea that green consumers are in favour of an eco-friendly progress and pay more attention to prices for those products. Equilibrium quantities are consequently given by:

$$
q_{i}^{*}\left(p_{i}^{*}\left(e_{i}, e_{j}\right), p_{j}^{*}\left(e_{i}, e_{j}\right)\right)=\frac{p_{i}^{*}}{1-\beta^{2}}
$$

Thus they have the same properties of prices with respect to $e_{j}$ and $\bar{e}$.

In the first stage, each firm $i$ maximises its profit with respect to its environmental quality $e_{i}$ :

\footnotetext{
${ }^{10}$ For simplicity, we abstract away from spillovers in the industry.

${ }^{11}$ See the appendix for the computation of consumer surplus.
} 


$$
\max _{e_{i}} \pi_{i}=\frac{\left[p_{i}^{*}\left(e_{i}, e_{j}\right)\right]^{2}}{1-\beta^{2}}-C_{i}\left(e_{i}, e_{j}\right) .
$$

The first order condition yields the best reply function for firm $i$ :

$$
e_{i}\left(e_{j}\right)=e(0)-\frac{\lambda^{2} \beta\left(2-\beta^{2}\right)}{\left(4-\beta^{2}\right)^{2}\left(1-\beta^{2}\right)-\lambda^{2}\left(2-\beta^{2}\right)^{2}} e_{j},
$$

where

$$
e(0)=\frac{\lambda\left(2-\beta^{2}\right)(1+\beta)(1-\beta)\left[(1-\lambda)\left(e_{m}+e_{0}\right) / 2+\alpha\right]}{\left(4-\beta^{2}\right)^{2}\left(1-\beta^{2}\right)-\lambda^{2}\left(2-\beta^{2}\right)^{2}},
$$

and the denominator is always positive. ${ }^{12}$ A preliminary result can be summarised in the next lemma:

Lemma 1 Green qualities are strategic substitutes.

$\mathbf{P}$ roof. See the Appendix

A firm's marginal revenue is sensitive to a change in its own environmental quality relative to a change in the rival's. Given the values of $\lambda$ and $\beta$, the magnitude of quality difference indicates the degree to which the consumers' perceive the two products are differentiated, or inversely, how close strategic substitutes the two products are from the firms' perspectives. Thus an increase of the environmental quality of the competitor increases the marginal return from investing in one's own quality. When the degree of substitutability increases, the two products become more homogeneous (lower differentiation or strategically perfect substitutes) and the firms' profits would drop to a lower level. Solving the system of (10), the equilibrium qualities are symmetric:

$$
e_{i}^{*}=\frac{\lambda\left(2-\beta^{2}\right)\left[\alpha+\left(e_{m}+e_{0}\right)(1-\lambda) / 2\right]}{(2-\beta)^{2}(1+\beta)(2+\beta)-\lambda^{2}\left(2-\beta^{2}\right)^{2}} .
$$

Condition $e_{i}^{*}>e_{0}$ holds for

$$
e_{0}<\widetilde{e}_{0} \equiv \frac{\lambda\left(2-\beta^{2}\right)\left[e_{m}(1-\lambda)+2 \alpha\right]}{2(2-\beta)^{2}(1+\beta)(2+\beta)+\lambda(1+\lambda)\left(2-\beta^{2}\right)} .
$$

Eq. (12) highlights the role played by the underestimation of consumers' perception and their belief that a higher environmental quality on the upper bound, $e_{m}$, signals an increase in the total environmental quality of the production process. The solution concept is therefore satisfied whenever the underestimation of perception is not too high, otherwise is not feasible. Moreover this symmetric outcome arises when the degree of substitution is not too high. Note that the equilibrium outcome of the pure vertically

\footnotetext{
${ }^{12}$ See the appendix
} 
differentiated duopoly model cannot realise as a limiting case of our model as $\beta$ tends to 1. The demand systems are quite distinct to the case with only vertical differentiation. In our system, each consumer buys a variable quantity of both goods, whereas she buys a single unit of one good in the purely vertical differentiation models. ${ }^{13}$ In equilibrium, firm $i$ 's prices and profits are respectively,

$$
p_{i}^{*}=\frac{\left(1-\beta^{2}\right)\left(4-\beta^{2}\right)}{\lambda\left(2-\beta^{2}\right)} e_{i}^{*},
$$

and

$$
\pi_{i}^{*}=\frac{\left(1-\beta^{2}\right)\left(4-\beta^{2}\right)^{2}-\lambda\left(2-\beta^{2}\right)^{2}}{\lambda^{2}\left(2-\beta^{2}\right)^{2}} e_{i}^{* 2} .
$$

We are now in a position to examine the characteristics of the equilibrium. Begin the comparative statics analysis by evaluating how a variation in the degree of substitutability influences the equilibrium quality, we obtain that:

Lemma 2 The investment in green quality decreases the more the goods are substitutes.

$\mathbf{P}$ roof. See the appendix.

Lemma 2 suggests that the equilibrium quality is directly related to the degree of product substitutability only if the relative extra cost of producing green quality is sufficiently low. The convenience of the investment places countervailing incentives on a firm's optimal level of quality. Lower margins decrease the immediate costs of production, but also reduce the opportunity to face higher price and greater demand motivated by consumers' environmental consciousness.

Consider further the analysis of a variation in the average perception of environmental quality. Differentiating the equilibrium qualities,

$$
\frac{\partial e_{i}^{*}}{\partial \bar{e}}=\frac{2 \lambda(2-\beta)\left(2-\beta^{2}\right)(1-\lambda)}{4(2-\beta)\left[2(1+\beta)(2+\beta)-\lambda^{2}\right]}>0 .
$$

The uncertainty about the value of the quality of a good has directly implications with personal misperception. In particular, given (15) together with (9), (13) and (14), it follows that,

Proposition 1 Qualities, prices, quantities and profits in equilibrium increase in the average misperception of environmental quality.

$\mathbf{P}$ roof. See the Appendix

The chain of evaluations leading from an increase in the misperception to an increase in profits, prices and quantities is fairly straightforward. Indeed Proposition 1 implies that, the higher the average quality perceived by the non-environmentally aware consumers, the larger the demand for firm's product and the higher the firms' incentives to invest in environmental quality due to a higher price in equilibrium.

\footnotetext{
${ }^{13}$ See Gabszewicz and Thisse $(1979,1980)$ and Shaked and Sutton (1982), inter alia.
} 


\section{Regulatory interventions}

Emissions taxes and environmental standards are widely considered as the most common policy instruments for regulation of environmental externalities. Taxes generally raise government revenue, while usually an environmental standard specifies with a certain degree of precision the actions that a firm should undertake to achieve certain objectives. ${ }^{14}$ An emission tax works through the market imposing a higher cost per unit of production. Pollution is therefore priced by the tax inducing entrepreneurs to release less of it. By leaving polluters free to choose their optimal emission levels, they can use their own strategy in order to minimize their costs. The optimal process for polluters minimizes their total private costs by reducing emissions until the tax rate equals their marginal abatement cost. This could be determined by any combination of pollution abatement or green innovation as in Sengupta (2012b).

The environmental standard requires firm's emission not to fall short of a given level. With perfect information and a definite quality standard, a firm has in principle the same total abatement costs as in the tax system, but unlike the tax system it does not have to pay for abatement. ${ }^{15}$ This result is confirmed in case of environmentally conscious consumers by Deltas et al. (2013). From a public policy view, the net social benefits of the tax or a standard set at the socially efficient level of emissions are identical. What differs is the impact on the polluters. We observe that these results are not true in case of imperfect information on quality since environmental standard bites if and only if the overestimation of the environmental quality $e_{m}$ is sufficiently high. ${ }^{16}$

The aim of this section is therefore to point out whether these instruments and their impacts are indeed best in the presence of market failures, such as the misperception on quality and the extreme case of greenwashing (Lyon and Maxwell, 2011). To uncover the importance of the misperception among consumers, we introduce in the next subsection both emission tax and environmental standard in our framework comparing their effects on quality and welfare.

\subsection{Tax on emissions}

Let us first introduce a tax on emissions in the system. Firm $i$ 's profit function is given by:

$$
\pi_{i}=p_{i} q_{i}\left(p_{i}, p_{j}\right)-C_{i}-t E,
$$

where taxation is a linear function of emissions, $E$ and $t$ is the unit tax. In turn, social welfare becomes

$$
S W=\sum_{i}^{1,2} \pi_{i}+C S-D+T,
$$

\footnotetext{
${ }^{14}$ See Holland (2012).

${ }^{15}$ See Bottega and De Freitas (2009).

${ }^{16}$ See Sengupta (2012a) for an alternative model in the presence of misperception of quality of green consumers.
} 
where $T=2 t E$ denotes total tax revenue. The market stage remains unchanged compared to the unregulated case. In the first stage, equilibrium qualities are:

$$
e_{i}^{t *}=-\frac{t(2-\beta)^{2}(1+\beta)(2+\beta)-2 \lambda\left[\bar{e}^{2}(1-\lambda)+\alpha\right]\left(2-\beta^{2}\right)}{2\left(2-\beta^{2}\right)\left[(1+\beta)(2+\beta)-\lambda^{2}\right]} .
$$

Eq. (17) underlines the role placed by the average misperception on quality level. In particular, it influences negatively the quality derived on tax emission. This result is still valid if the degree of substitution is high. Comparing the level of qualities with the (previous) unregulated case we get,

$$
e_{i}^{*}-e_{i}^{t *}=-\frac{t(2-\beta)^{2}(1+\beta)(2+\beta)}{2\left(2-\beta^{2}\right)\left[(1+\beta)(2+\beta)-\lambda^{2}\right]}<0 .
$$

Therefore,

Proposition 2 The introduction of a tax on polluting emission increases the investment in environmental quality.

$\mathbf{P}$ roof. See the Appendix

A tax on emission increases in the so-called long run effect (quality choice) as demonstrated by Oueslati (2014), although the effect over short run (price choice) is ambiguous and is entirely due to uncertainty in perception of green consumers. By introducing a Pigouvian tax, the objective of investing in environmental quality becomes two-fold: a firm invests in green quality in order to acquire green consumers, meanwhile, the investment reduces fiscal costs.

Now suppose that there is a pre-stage where government sets a Pigouvian tax with the aim to maximise social welfare. The first order condition of $S W$ with respect to $t$ yields the socially optimal tax $t^{*} \cdot{ }^{17}$ The result can be summarised as follows ${ }^{18}$ :

Proposition 3 The level of optimal taxation

- increases with the marginal damage of emissions when $\bar{e}>\widetilde{e}$.

- decreases with the average perception of environmental quality when $d>\widetilde{d}$.

\footnotetext{
${ }^{17}$ See the appendix.

${ }^{18}$ See the appendix for definitions of $\widetilde{e}, \widetilde{d}$ and proofs.
} 


\section{$\mathbf{P}$ roof. See the Appendix}

If the marginal damage of emission is high, at the optimal level, the increase of demand needs to be compensated by higher taxation. When production is very polluting, the optimal tax burden is heavy. Higher perception of environmental quality induces greater demand functions such that a lower level of taxation is sufficient to reach the optimum. Further, we examine how the optimal tax reacts to the presence of greenwashing by the analysis of a variation in $e_{m}$. Differentiating $t^{*}$ with respect to $e_{m}$ yields:

$$
\frac{\partial t^{*}}{\partial e_{m}}>0
$$

for $d<\widetilde{d}$.

\section{$\mathbf{P}$ roof. See the Appendix}

Eq. (19) shows that an increase in the quality upper bound positively influences the endogenous level of taxation. This echoes an argument about the effect of greenwashing in regulatory terms. The misperception in quality (and in particular a potential rise in the upper bound, $e_{m}$ ) allows firms to use their production profile to create an eco-friendly image of themselves. An instance is the traditional activity of loggers in developing countries. ${ }^{19}$ In this case, the misperception helps to support higher level of taxation since the incentives on green products rise meanwhile. This means that, although the aggregate emission is lower, the green consumers' uncertainty allows higher profits for the firms. As a consequence, total abatement costs and the derived damages for each unit of emissions are not the same as in the endogenous evaluation of tax rate.

\subsection{Environmental standard}

In this section we introduce an environmental standard that sets the minimum level of environmental quality. It is generally defined by regulation which specifies the maximum permissible concentration of a potentially hazardous chemical in an environmental sample. We denote it in our model as $\widehat{e}>e_{0}$, i.e., a predetermined value higher than the lower bound in misperception. Whenever $\widehat{e}>e_{0}$, eco-friendly consumers, who receive the low quality signal for good $i$, revise their beliefs and update it to $e_{0}=\widehat{e}$. This increases their willingness to pay for that product. Begin by evaluating how this influences the quality investment in equilibrium. Differentiating $e_{1}^{*}$ and $e_{2}^{*}$ with respect to $e_{0}$, it yields:

$$
\frac{\partial e_{i}^{*}}{\partial e_{0}}=\frac{\lambda\left(2-\beta^{2}\right)(1-\lambda)}{2(2-\beta)^{2}\left[(1+\beta)(2+\beta)-2 \lambda^{2}\right]}>0 .
$$

This result implies that the environmental standard has a positive impact on firms' qualities satisfying the higher need of green products.

\footnotetext{
${ }^{19}$ During the razing of rainforests, World Wildlife Fund (WWF) was accused to be soft on the loggers and allowed them to use the iconic panda logo of WWF. The most evident case was the Malaysian one, http://www.globalwitness.org/sites/default/files/pdfs/Pandering_to_the_loggers.pdf
} 
Proposition 4 Introducing an environmental standard increases the quality investment of both firms.

\section{$\mathbf{P}$ roof. See the Appendix}

The higher willingness to pay of consumers in turn affects the firms' incentives to invest in environmental quality. The consumers' signal about the environmental performance of the firms creates an incentive for the latters to act differently with respect to the case of symmetric information. The implementation of a standard guarantees a higher level of green type due to the exogenous threshold. With regards to the effect of substitutability among goods, we differentiate with respect to $\beta$ such that:

$$
\frac{\partial e_{i}^{*}}{\partial e_{0} \partial \beta}=-\frac{\lambda\left(8-8 \beta-2 \beta^{2}+8 \beta^{3}+\beta^{4}-2 \beta^{5}\right)(1-\lambda)}{2\left[8+4 \beta-\beta^{3}+\beta^{4}-2 \lambda^{2}-\beta^{2}\left(6-\lambda^{2}\right)\right]^{2}}<0 .
$$

This implies that the substitutability among goods, $\beta$, reduces the impact of this policy in the market. Even if regulatory authorities (through environmental standard) succeed in inducing cleaner products among firms, its success (and efficacy) entirely depends on the substitutability of the products. This is due to the lack of strategic effects. Moreover, the higher willingness to pay for green products induces firms to invest in higher quality and green innovation. This effect is still higher, the more the goods are substitutes. Let us evaluate how the impact of the environmental standard influences qualities, prices, quantities and profits. According to Proposition 1 and observing the role of the standard, it follows that:

Proposition 5 Qualities, prices, quantities and profits rise in equilibrium if an environmental standard, $\widehat{e}$, is introduced such that $\widehat{e}>e_{0}$.

$\mathbf{P}$ roof. See the Appendix

Since the consumers' willingness to pay is increased with respect to the unregulated case, thus their demand for both goods shifts up. Firms offer goods of higher quality (Proposition 5), so that they can also charge higher prices. In turn profits increase.

Consider next the introduction of an endogenous environmental standard. ${ }^{20}$ Suppose that there is a pre-stage in which the government sets an environmental standard $\widehat{e}>e_{0}$ so as to maximise social welfare. Consumers will update their evaluation of the lower bound of environmental quality, so that $e_{0}^{*}=\widehat{e}$. The first order condition with respect to $e_{0}$ yields $e_{0}^{*} \cdot{ }^{21}$ Differentiating $e_{0}^{*}$ with respect to $e_{m}$ yields:

$$
\frac{\partial e_{0}^{*}}{\partial e_{m}}>0
$$

\footnotetext{
${ }^{20}$ See Ecchia and Lambertini (1997) for an analysis of endogenous minimum quality standard.

${ }^{21}$ See the appendix.
} 
for $d<\widehat{d}^{22}$ Eq. (22) suggests that if the environmental damage in the industry is relative low, the overestimation of the environmental quality of the green consumers has a positive effect on the optimal level of lower bound. Thus in case of uncertain qualities, greenwashing behaviour drives a rise in the optimal endogenous standard of the firms and guarantees an effective policy by the government. In other words, whether the relative dirty types partially imitate the clean ones, this ensures beneficial impact in terms of profits due to environmental consciousness. This is possible only if the emissions are not so harmful or relatively limited over time. Otherwise, the presence of greenwashing reduces the endogenous threshold motivated by lower expected returns.

The next question is whether or not the introduction of an optimal environmental standard would bite, i.e., if it indeed affect the level of investment in environmental quality of the firm or not. Comparing $\widehat{e}^{*}$ with $e_{i}^{*}$, i.e., the equilibrium quality in the unregulated case yields:

$$
e_{0}^{*}-e_{i}^{*}>0
$$

for

$$
e_{m}>\widetilde{e}_{m}
$$

where $\widetilde{e}_{m}$ is defined in the appendix. Hence

Proposition 6 An optimal environmental standard bites only if the overestimation of the environmental quality $e_{m}$ is sufficiently high.

$\mathbf{P}$ roof. See the Appendix

Proposition 6 shows how the perception of environmental quality may affect the effectiveness of a policy based on environmental standards. In particular, when consumers' overestimation, $e_{m}$, is high, demands increase even in case of low perception. Indeed, firms are willing to invest less in environmental quality since consumers overestimate it considerably. In this case, the introduction of an optimal environmental standard induce firms to invest more in quality, and therefore, it is an effective regulatory tool in industries where greenwashing is adopted. Notice that there is no trade-off between consumer surplus and damage function. This is due to the fact that the quality is green and consumers internalise it in their utility function, so that incentives are aligned. This effect does not emerge in situations where quality is hedonic. In this case, an increase in consumer surplus would imply higher emissions (Lambertini and Tampieri, 2012 and Ecchia et al., 2013).

\subsection{Emission tax vs environmental standard}

We now propose a simple simulation to investigate the impact of the two policies on quality levels. Unlike the case of perfect information, where the effect on qualities is analogous between the two interventions (Holland, 2012), we show that the misperception

\footnotetext{
${ }^{22}$ See the appendix for eq. (22) and the definition of $\widehat{d}$ defined in (27).
} 
in qualities determines a different effect of the emission tax and the standard. The results entirely depend on the value of emissions produced by the firms. First, it is worth to point out that introducing the emission standard does not change the ranking in qualities whenever the value of greenwashing is relatively low as demonstrated by Proposition 6 . The only alternative in this case is to apply a tax per unit of emission costs. Hence in the simulation we set the conditions on $e_{m}$ such that the environmental standard is biting (see the appendix). Whether the misperception is high, instead, the quality levels determined by the two policies depend on the level of emissions generated by the firms.

We assume generic values of the parameters of the model: the proportion of green consumers able to perceive the true quality, $\lambda$, is equal to 0.1 ; the substitutability among goods, $\beta$, is assumed to be 0.3 ; while, the constant coefficient $\alpha$ is 1 . Figure 1 summarises the results. For lower level of damage, $d$, the environmental standard with misperception ensures higher level of quality. This supports the idea that, for limited levels of emission, the impact of greenwashing is still higher under the standard than under the tax. A similar effect occurs from the underestimation. The results are not confirmed for higher value of damages, where a tax on emission guarantees higher level of environmental quality. This shift occurs since an emission tax imposes a higher unit of production cost and its impact expands for higher level of emissions rising the abatement costs has shown above.

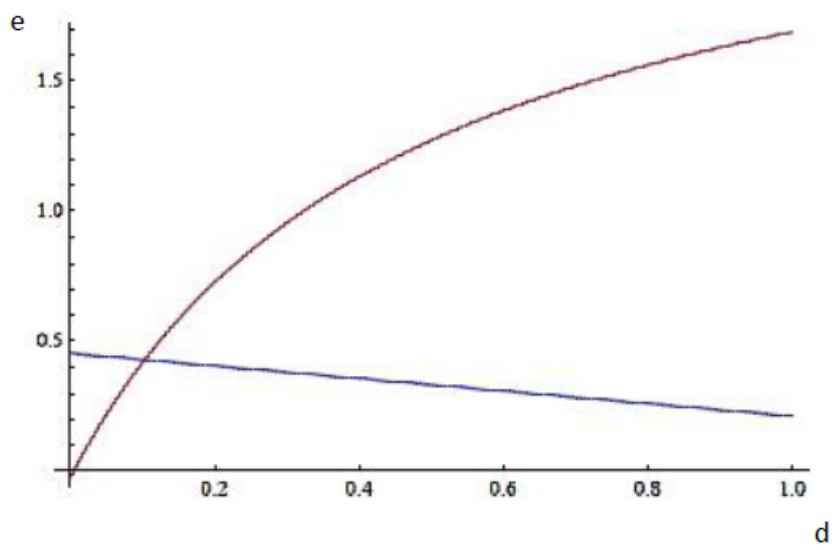

Figure 1: Emission tax vs environmental standard

As a general perspective this implies that an environmental standard accompanied by greenwashing behaviour increases the effective marginal cost more than the tax for lower amount of damages. Both interventions increase the effective marginal cost of production, exert an ongoing pressure on price competition and reduce the output of the not eco-friendly products. However a lower quality of the green products is ensured under the standard whenever the polluting amount is high and is not overcompensated by potential misperception.

The welfare realisations for consumers between the two policies might in principle depend on the relative change in consumption due to environmental awareness. The effect could be even higher with asymmetric technology among firms. The idea is that the 
importance of environmental perception is reduced whenever one firm is more efficient than the competitor. This proxies the market power of the efficient firm with higher profits as quality increases. Accordingly, the weight of overestimation (and in turn greenwashing) in determining prices is relatively lower than in the symmetric case, since profits for the efficient firm grow more than its less efficient competitor. By the same token, the level of $\bar{e}$ has a lower weight for the efficient firm than for the inefficient one. It is higher in the presence of an environmental standard rather than with a tax on emission, since the former policy does not affect production costs. These impacts could be so large under the standard relative to the tax that outweighs the reduction in the environmental quality of the products. Other analysis on this point could be left for future research.

\section{Concluding remarks}

The misperception in environmental quality and the potential greenwashing behaviour of firms are arguably one of the most important effects able to influence the market size.

In a world of asymmetric information where green consumers misperceive the environmental quality of the product and the consequent damage caused by firm's production, we have analysed the effect of regulatory intervention as well as the incentive to invest in cleaner process according to the aggregate emission level. Our framework evaluates a two-stage game where companies first maximise their profits, while, in the second stage, firms set prices according to the individual perception on quality.

We show that consumers have different perceptions on quality, they are not able to observe both the investment decision of the firm and the realised performance in terms of innovation process and total emission. The heterogeneity of information that agents can receive guarantees higher profits for firms and the effect is higher, the larger is the impact of greenwashing in the market due to the overestimation of the signal. 


\section{References}

[1] André, F.J., González, P. and Porteiro, N. 2009. Strategic quality competition and the Porter hypothesis. Journal of Environmental Economics and Management 57: 182-194.

[2] Arora, S. and Gangopadhyay, S. 1995. Toward a theoretical model of voluntary overcompliance. Journal of Economic Behavior and Organization 28: 289-309.

[3] Bansal, S and Gangopadhyay, S. 2003. Tax/subsidy policies in the presence of environmentally aware consumers. Journal of Environmental Economics and Management 45: 333-355.

[4] Bottega, L. and De Freitas, J. 2009. Public, Private and Nonprofit Regulation for Environmental Quality. Journal of Economics and Management Strategy 18: 105123.

[5] Chang, C.-H. 2Consumers keen on green but marketers don't deliver. Advertising Age 63: 2-4.

[6] Chase, D. and Smith, T.K., 1992. ompetitive Investment in Clean Technology and Uninformed Green Consumers. Auburn Economics Working Paper Series auwp201208

[7] Chen, Y.S. 2008. The driver of green innovation and green image - Green core competence. Journal of Business Ethics 81: 531-543.

[8] Chen, Y.S. and Chang, C.H. 2013. Greenwash and green trust: the mediation effects of green consumer confusion and green perceived risk. Journal of Business Ethics 114: $489-500$.

[9] Conrad, K. 2005. Price competition and product differentiation when consumers care for the environment. Environmental and Resource Economics 31: 1-19.

[10] Cremer, H. and Thisse, J.F. 1999. On the Taxation of polluting products in a differentiated industry. European Economic Review 43: 575-594.

[11] Delmas, M, and Lessem, N. 2014. Saving power to conserve your reputation? The effectiveness of private versus public information. Journal of Environmental Economics and Management 67: 353-370.

[12] Deltas G., Harrington D. R., Khanna M., 2013. Oligopolies with (Somewhat) Environmentally Conscious Consumers: Market Equilibrium and Regulatory Intervention. Journal of Economics and Management Strategy 22: 640-667.

[13] Doni, N. and Ricchiuti, G. 2013. Market equilibrium in the presence of green consumers and responsible firms: A comparative statics analysis. Resource and Energy Economics 35: 380-395. 
[14] Ecchia, G., Lambertini, L. 1997. Minimum Quality Standards and Collusion, Journal of Industrial Economics 45: 101-113

[15] Ecchia, G., Lambertini, L. and Tampieri, A. 2013. Minimum quality standards in hedonic markets with environmental externalities. Environmental Modeling and Assessment 18: 319-323.

[16] Eriksson, C. 2004. Can green consumerism replace environmental regulation? A differentiated-products Examples. Resource and Energy Economics 26: 281-293.

[17] Garella, P. G., and Petrakis, E. 2008. Minimum Quality Standards and Consumers' Information. Economic Theory 36: 283-302.

[18] Garcia-Gallego, A. and Georgantzís, N. 2009. Market effects of changes in consumers' social responsibility. Journal of Economics and Management Strategy, 19: 453-487.

[19] Häckner, J. 2000. A note on price and quantity competition in differentiated oligopolies. Journal of Economic Theory 93: 233-239.

[20] Holland, S. 2012. Emissions taxes versus intensity standards: Second-best environmental policies with incomplete regulation. Journal of Environmental Economics and Management 63: 375-387.

[21] Kim, Y. and Choi, S.R. 2005. Antecedents of green purchase behaviour: An examination of collectivism, environmental concern and PCE. Advances in Consumer Research 32: 592-599.

[22] Kohl, M. F., 1991. Good Earth Art. Bellingham: Bright Ring Publishing.

[23] Lambertini, L. and Tampieri, A. 2012a. Do minimum quality standards bite in polluting industries? Research in Economics 66: 184-194.

[24] Lambertini, L. and Tampieri, A. 2012b. Vertical differentiation in a Cournot industry: The Porter hypothesis and beyond. Resource and Energy Economics 34: 374-380.

[25] Lyon, T.P. and Maxwell J. W. 2011. Greenwash: Corporate Environmental Disclosure under Threat of Audit, Journal of Economics and Management Strategy 20: $3-41$

[26] Lombardini-Riipinen, C. 2005. Optimal tax policy under environmental quality competition. Environmental and Resource Economics 32: 317-336.

[27] Moraga-Gonzalez, J. L. and Padron-Fumero, N. 2002. Environmental policy in a green market. Environmental and Resource Economics 22: 419-447.

[28] Oueslati, W. 2014. Environmental tax reform: Short-term versus long-term macroeconomic effects, Journal of Macroeconomics 40: 190-201. 
[29] Reitman, V. 1992. Green products sales seem to be wilting. The Wall Street Journal 220: 18

[30] Sengupta, A. 2012a. Investment in Cleaner Technology and Signaling Distortions in a Market with Green Consumers, Journal of Environmental Economics and Management 64: $468-480$

[31] Sengupta, A. 2012b. The influence of corporate environmental ethics on competitive advantage: The mediation role of green innovation. Journal of Business Ethics 104: 361-370. 


\section{Appendix}

\subsection{Consumer surplus}

By evaluating the sum of utilities, consumer surplus is:

$$
\begin{aligned}
C S= & \frac{1}{1-\beta^{2}}\left[2\left(p_{1}^{* 2}+p_{2}^{* 2}+e_{m}^{2}\right)+4 \alpha(1-\beta)\left(\alpha+e_{m}+e_{0}\right)-2 p_{2}^{*}\left(2 \alpha+e_{m}+e_{0}\right)(1-\beta)+\right. \\
& -\beta\left(e_{0}+e_{m}\right)^{2}-2 p_{2}^{*} \lambda\left(2 e_{2}^{*}-\left(e_{m}+e_{0}\right)(1-\beta)-2 e_{1} \beta\right)+ \\
& -2 \lambda\left(\left(e_{m}+e_{0}-e_{1}^{*}-e_{2}^{*}\right)\left(e_{m}+e_{0}-e_{1}^{*}-e_{2}^{*}-\beta\left(2 \alpha+e_{m}+e_{0}\right)-2 \alpha\right)\right)+ \\
& -\lambda^{2} \beta\left(e_{m}+e_{0}-2 e_{1}^{*}\right)\left(e_{m}+e_{0}-2 e_{2}^{*}\right) \\
& \left.-2 p_{1}^{*}\left(\left(e_{m}+e_{0}\right)(1-\beta)(1-\lambda)+2\left(\alpha+p_{2}^{*} \beta+e_{1}^{*} \lambda-\alpha \beta-e_{2}^{*} \lambda \beta\right)\right)\right] .
\end{aligned}
$$

\subsection{Proof of Lemma 1}

The second order conditions of $\pi_{i}$ with respect to $e_{i}$ yields:

$$
\frac{\partial^{2} \pi_{i}}{\partial e_{i}^{2}}=\frac{2 \lambda^{2}\left(2-\beta^{2}\right)^{2}}{\left(4-\beta^{2}\right)^{2}\left(1-\beta^{2}\right)}-2<0
$$

for

$$
\lambda^{2}<\widehat{\lambda}^{2} \equiv \frac{\left(4-\beta^{2}\right)^{2}\left(1-\beta^{2}\right)}{\left(2-\beta^{2}\right)^{2}} .
$$

Thus the problem admits a maximum when the group of fully aware consumers is not too

large. Note also that $\widehat{\lambda}^{2}(1)=0$, implying that the equilibrium requires some substitutability among goods. Condition (24) implies the positivity of best reply (10) and is sufficient condition in order to get substitutability in quality investments.

\subsection{Proof of Lemma 2}

Differentiating $e_{i}^{*}$ with respect to $\beta$ yields:

$$
\frac{\partial e_{i}^{*}}{\partial \beta}=\frac{\lambda\left(8-8 \beta-2 \beta^{2}+8 \beta^{3}+\beta^{4}-2 \beta^{5}\right)\left[\left(e_{m}+e_{0}\right)(1-\lambda) / 2+2 \alpha\right]}{2\left[8+4 \beta-\beta^{3}+\beta^{4}-2 \lambda^{2}-\beta^{2}\left(6-2 \lambda^{2}\right)\right]^{2}}<0 .
$$




\subsection{Characterization of the Endogenous Tax}

The first order condition of the Social Welfare Function $S W$ with respect to $t$ yields the optimal level of taxation:

$$
t^{*}=A+\bar{e} B
$$

where

$$
\begin{gathered}
A=\frac{4 d \bar{e}\left(2+\beta-\beta^{2}\right)^{2}\left(2-\beta-\beta^{2}\right)+2 \alpha \lambda\left(1-\beta^{2}\right)\left[2-\beta-4 d\left(2-\beta^{2}\right)\right]+2 \lambda^{2}\left(2-\beta^{2}\right)\left[\alpha-2 d \bar{e}\left(1-\beta^{2}\right)\right]+2 \alpha \lambda^{3}}{2(1+2 d)\left(2+\beta-\beta^{2}\right)^{2}\left(2-\beta-\beta^{2}\right)-\lambda(2-\beta)^{2}(1+\beta)(2+\beta)+\lambda^{2}(1+\beta)(2+\beta)[1+\beta(1-\beta)]} \\
B=\frac{2 \lambda(1-\lambda)\left[6+4 d\left(2-3 \beta^{2}+\beta^{4}\right)-2 \lambda+\beta(5-\beta(4+\beta(2-\beta)-\lambda))\right]}{2(1+2 d)\left(2+\beta-\beta^{2}\right)^{2}\left(2-\beta-\beta^{2}\right)-\lambda(2-\beta)^{2}(1+\beta)(2+\beta)+\lambda^{2}(1+\beta)(2+\beta)[1+\beta(1-\beta)]}
\end{gathered}
$$

\subsection{Proof of Proposition 3}

Begin by examining the variation of the optimal tax to a change in the marginal damage of emissions. Differentiating $t^{*}$ with respect to $d$ yields:

$$
\begin{gathered}
\frac{\partial t^{*}}{\partial d} \propto 8(1-\beta)\left(1+\beta-\beta^{2}\right)(1-\lambda)\left[8+4 \beta-\beta^{3}+\beta^{4}-2 \lambda^{2}-\beta^{2}\left(6-\lambda^{2}\right)\right] \bar{e}+ \\
-4 \lambda(1-\beta)\left[8+4 \beta-\beta^{3}+\beta^{4}-2 \lambda^{2}-\beta^{2}\left(6-\lambda^{2}\right)\right]\left[2 \alpha \lambda\left(3-5 \beta+2 \beta^{2}\right)\right]+ \\
-\bar{e}\left[8+8 \beta^{3}-2 \beta^{4}-4 \lambda+\lambda^{2}+\beta^{2}\left(6+\lambda+\lambda^{2}\right)+\beta\left(8-4 \lambda-\lambda^{2}\right)\right]>0,
\end{gathered}
$$

if and only if

$$
\bar{e}>\widetilde{e}
$$

where

$$
\begin{aligned}
\widetilde{e} \equiv & \frac{4 \lambda(1-\beta)\left[8+4 \beta-\beta^{3}+\beta^{4}-2 \lambda^{2}-\beta^{2}\left(6-\lambda^{2}\right)\right]\left[2 \alpha \lambda\left(3-5 \beta+2 \beta^{2}\right)\right]}{8(1-\beta)\left(1+\beta-\beta^{2}\right)(1-\lambda)\left[8+4 \beta-\beta^{3}+\beta^{4}-2 \lambda^{2}-\beta^{2}\left(6-\lambda^{2}\right)\right]} \\
& +\frac{\bar{e}\left[8+8 \beta^{3}-2 \beta^{4}-4 \lambda+\lambda^{2}+\beta^{2}\left(6+\lambda+\lambda^{2}\right)+\beta\left(8-4 \lambda-\lambda^{2}\right)\right]}{8(1-\beta)\left(1+\beta-\beta^{2}\right)(1-\lambda)\left[8+4 \beta-\beta^{3}+\beta^{4}-2 \lambda^{2}-\beta^{2}\left(6-\lambda^{2}\right)\right]}
\end{aligned}
$$

Next, we investigate how a change in the perception of environmental quality would influence the optimal level of taxation. By differentiating $t^{*}$ with respect to the average perception of environmental quality, it yields: 
$\frac{\partial t^{*}}{\partial \bar{e}}=\frac{2 \lambda(1-\lambda)\left[6+4 d\left(2-3 \beta^{2}+\beta^{4}\right)+2 \lambda-\beta(5-\beta(4+\beta(2-\beta)-\lambda))\right]}{\left[\lambda(2-\beta)^{2}-\lambda^{2}[1-\beta(1-\beta)]\right](1+\beta)(2+\beta)-2(1+2 d)\left(2+\beta-\beta^{2}\right)^{2}\left(2-\beta-\beta^{2}\right)}<0$

if and only if,

$$
d>\widetilde{d} \equiv \frac{\lambda[4-\lambda-\beta(4+\lambda-\beta(1+\lambda))]}{4(2-\beta)^{2}\left(1-\beta^{2}\right)}-\frac{1}{2}
$$

The cross derivative of $t^{*}$ with respect to $\bar{e}$ and $d$ confirms the results above:

$$
\frac{\partial t^{*}}{\partial \bar{e} \partial d} \propto(2-\beta)^{2}(1+\beta)(2+\beta)-\lambda^{2}\left(2-\beta^{2}\right)>0
$$

\subsection{Proof of eq. (19)}

Differentiating $t^{*}$ with respect to $e_{m}$ yields:

$$
\frac{\partial t^{*}}{\partial e_{m}}=-\frac{\lambda(1-\lambda)\left[6+4 d\left(2-3 \beta^{2}+\beta^{4}\right)-2 \lambda+\beta(5-\beta(4+2 \beta(2-\beta)+\lambda))\right]}{(1+\beta)(2+\beta)\left[\lambda(2-\beta)^{2}-\lambda^{2}(1+\beta(1-\beta))\right]-2(1+2 d)\left(2+\beta-\beta^{2}\right)^{2}\left(2-\beta-\beta^{2}\right)}>0
$$

\subsection{Characterization of the Endogenous Standard}

The first order condition of $S W$ with respect to $t$ yields the optimal level of taxation:

$$
e_{0}^{*}=C+e_{m} F
$$

such that

$$
C=\frac{2}{\left(2-\beta^{2}\right)} \frac{\Phi-\Psi}{\Lambda-\Gamma} \quad \text { and } \quad F=\frac{1}{\left(2-\beta^{2}\right)} \frac{\digamma}{\Lambda-\Gamma}
$$

where variables $\Phi, \Psi, \Lambda, \Gamma, \digamma$ respectively indicating,

$$
\begin{aligned}
\Phi & =2 d \lambda \bar{e}(1-\beta)\left(2-\beta^{2}\right)(2+\beta)\left(2+\beta-\beta^{2}\right)^{2}\left(2-\beta^{2}\right)-\alpha(2-\beta)^{2}(1-\beta)(1+\beta)^{2}(2+\beta)^{2}(3-2 \beta) \\
\Psi & =\alpha \lambda^{2}(1+\beta)\left(2-\beta^{2}\right)\left[12+4 d(1-\beta)\left(2-\beta^{2}\right)-\beta(8-\beta(4-3 \beta))\right]-\lambda^{3}\left(2-\beta^{2}\right)^{2}\left[\alpha-2 d \bar{e}\left(1-\beta^{3}\right)\right] \\
\Lambda & =2 \lambda^{2}(1+\beta)\left[18+2 d(1-\beta)\left(2-\beta^{2}\right)-\beta(10-\beta(5-3 \beta))\right]-(1+\beta)^{2}[7-3 \beta(3-\beta)+\lambda(1+\beta(1-\beta))] \\
\Gamma & =\lambda^{3}\left[3-2 \beta^{2}+4 d\left(1-\beta^{2}\right)\right]+\lambda^{4} \\
\digamma & =2 \lambda^{2}(1+2 d)(2-\beta)^{2}\left(1-\beta^{2}\right)-(1-\lambda)\left[(2-\beta)^{2}(1+\beta)^{2}(2+\beta)^{2}(1+\beta(1-\beta))\right]-\lambda^{3}\left(2-\beta^{2}\right)^{2}
\end{aligned}
$$




\subsection{Proof of eq. (22):}

Given eq. (26), it can be easily shown that $\frac{\partial e_{0}^{*}}{\partial e_{m}}=F$. This is positive if and only if:

$$
\begin{gathered}
d<\widehat{d} \equiv \frac{(2-\beta)^{2}(1+\beta)^{2}(2+\beta)^{2}[7-3 \beta(3-\beta)+\lambda(1+\beta(1-\beta))]}{4 \lambda^{2}\left(2-\beta^{2}\right)^{2}\left(1-\beta^{2}\right)(1-\lambda)}+ \\
+\frac{\lambda^{3}\left(3-2 \beta^{2}\right)\left(2-\beta^{2}\right)^{2}-2 \lambda^{2}(1+\beta)\left(2-\beta^{2}\right)[18-\beta(10+\beta(5-3 \beta))]}{4 \lambda^{2}\left(2-\beta^{2}\right)^{2}\left(1-\beta^{2}\right)(1-\lambda)}
\end{gathered}
$$

\subsection{Proof of Proposition 6}

It is enough to prove that

$$
e_{m}>\widetilde{e}_{m} \equiv \frac{\chi+\psi}{\varrho+\vartheta}
$$

where now all the variables $\chi, \psi, \varrho, \vartheta$ respectively indicating,

$$
\begin{aligned}
\chi & =2 \alpha(1-\beta)(1+\beta)(3-2 \beta)\left(4-\beta^{2}\right)^{2}+\lambda(2-\beta)^{2}(2+\beta)\left(2-\beta^{2}\right)\left[\alpha+4 d \bar{e}\left(1-\beta^{2}\right)\right] \\
\psi & =\lambda^{2}\left(2-\beta^{2}\right)\left[2 d(\bar{e}+4 \alpha)(1-\beta)\left(2-\beta^{2}\right)+\alpha[16-\beta(12-\beta(6-5 \beta))]\right]-2 d \bar{e} \lambda^{3}(1-\beta)\left(2-\beta^{2}\right)^{2} \\
\varrho & =\left(1+2 \beta-\beta^{3}\right)\left(4-\beta^{2}\right)^{2}-\lambda^{2}(2-\beta)^{2}(2+\beta)[4+\beta(5-\beta(1-\beta(2+\beta)))] \\
\vartheta & =\lambda^{2}\left(2-\beta^{2}\right)\left[12+4 d(1-\beta)\left(2-\beta^{2}\right)-\beta[8-\beta(4-3 \beta)]\right]-2 \lambda^{3}(1+2 d)(1-\beta)\left(2-\beta^{2}\right)^{2}
\end{aligned}
$$




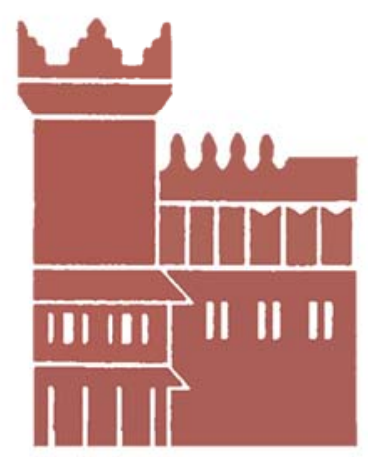

Alma Mater Studiorum - Università di Bologna DEPARTMENT OF ECONOMICS

Strada Maggiore 45

40125 Bologna - Italy

Tel. +39051 2092604

Fax +390512092664

http://www.dse.unibo.it 